Published in final edited form as:

Am J Perinatol. 2010 November ; 27(10): 791-796. doi:10.1055/s-0030-1254238.

\title{
MATERNAL AND NEONATAL OUTCOMES OF REPEAT CESAREAN DELIVERY IN WOMEN WITH A PRIOR CLASSICAL VERSUS LOW TRANSVERSE UTERINE INCISION
}

Tiki Bakhshi, M.D., Mark B. Landon, M.D., Yinglei Lai, Ph.D., Catherine Y. Spong, M.D., Dwight J. Rouse, M.D., Kenneth J. Leveno, M.D., Michael W. Varner, M.D., Steve N. Caritis, M.D., Paul J. Meis, M.D., Ronald J. Wapner, M.D., Yoram Sorokin, M.D., Menachem Miodovnik, M.D., Marshall Carpenter, M.D., Alan M. Peaceman, M.D., Mary J. O’Sullivan, M.D., Baha M. Sibai, M.D., Oded Langer, M.D., John M. Thorp, M.D., and Brian M. Mercer, M.D. for the Eunice Kennedy Shriver National Institute of Child Health and Human Development Maternal-Fetal Medicine Units Network, Bethesda, MD

Corresponding author: Tiki Bakhshi, MD Dept of OB/GYN Tripler Army Medical Center 1 Jarrett White Rd Honolulu, Hawaii 96859-5000 Phone : 808-433-2850 Fax: 808-433-3618 tiki.bakhshi@amedd.army.mil.

In addition to the authors, other members of the Eunice Kennedy Shriver National Institute of Child Health and Human Development Maternal-Fetal Medicine Units Network are as follows:

Vanderbilt University Medical Center — MFMU Steering Committee Chair — S. Gabbe

The University of Texas Health Science Center at Houston - S. Blackwell, S. Ramin, L. Gilstrap, M. Day, M. Kerr, E. Gildersleeve The Ohio State University — J. Iams, F. Johnson, S. Meadows, H. Walker

University of Alabama at Birmingham - D. Rouse, A. Northen, S. Tate

University of Texas Southwestern Medical Center - S. Bloom, J. Gold, D. Bradford

University of Utah - M. Belfort. (Utah Valley Regional Medical Center), F. Porter (Intermountain Healthcare), B. Oshiro (McKayDee Hospital Center), K. Anderson (University of Utah Health Sciences Center), A. Guzman (McKay-Dee Hospital Center)

University of Chicago - A.H. Moawad, J. Hibbard, P. Jones, M. Ramos-Brinson, M. Moran, D. Scott

University of Pittsburgh - K. Lain, M. Cotroneo, D. Fischer, M. Luce

Wake Forest University Health Sciences - M. Harper, M. Swain, C. Moorefield, K. Lanier, L. Steele

Thomas Jefferson University — A. Sciscione, M. DiVito, M. Talucci, M. Pollock

Wayne State University — M. Dombrowski, G. Norman, A. Millinder, C. Sudz, B. Steffy

University of Cincinnati — T. Siddiqi, H. How, N. Elder

Columbia University - F. Malone, M. D’Alton, V. Pemberton, V. Carmona, H. Husami

Brown University - H. Silver, J. Tillinghast, D. Catlow, D. Allard

Northwestern University — M. Socol, D. Gradishar, G. Mallett

University of Miami — G. Burkett, J. Gilles, J. Potter, F. Doyle, S. Chandler

University of Tennessee - W. Mabie, R. Ramsey

University of Texas at San Antonio - D. Conway, S. Barker, M. Rodriguez

University of North Carolina - K. Moise, K. Dorman, S. Brody, J. Mitchell

Case Western Reserve University - P. Catalano, C. Milluzzi, B. Slivers, C. Santori

The George Washington University Biostatistics Center - E. Thom, H. Juliussen-Stevenson, M. Fischer, Lucy Leuchtenburg

Eunice Kennedy Shriver National Institute of Child Health and Human Development - D. McNellis, K. Howell, S. Pagliaro

Presented at the 28th Annual Meeting of the Society of Maternal Fetal Medicine in Dallas, Texas in Jan 28-Feb 2, 2008. 
Departments of Obstetrics and Gynecology at The University of Texas Health Science Center at Houston, Houston, TX; The Ohio State University, Columbus, $\mathrm{OH}$; University of Alabama at Birmingham, Birmingham AL; University of Texas Southwestern Medical Center, Dallas, TX; University of Utah, Salt Lake City, UT; University of Pittsburgh, Pittsburgh PA; Wake Forest University Health Sciences, Winston-Salem, NC; Thomas Jefferson University, Philadelphia, PA; Wayne State University, Detroit, MI; University of Cincinnati, Cincinnati, OH; Columbia University, New York, NY; Brown University, Providence, RI; Northwestern University, Chicago, IL; University of Miami, Miami, FL; University of Tennessee, Memphis, TN; University of Texas Health Science Center at San Antonio, San Antonio, TX; University of North Carolina at Chapel Hill, Chapel Hill, Case Western Reserve University Cleveland, $\mathrm{OH}$; NC; and The George Washington University Biostatistics Center, Washington, DC and the Eunice Kennedy Shriver National Institute of Child Health and Human Development, Bethesda, MD.

\section{Abstract}

We compared maternal and neonatal outcomes following repeat cesarean delivery (CD) of women with a prior classical $\mathrm{CD}$ with those with a prior low transverse $\mathrm{CD}$. The Maternal Fetal Medicine Units (MFMU) Network Cesarean Delivery Registry was used to identify women with one previous $\mathrm{CD}$ who underwent an elective repeat $\mathrm{CD}$ prior to the onset of labor $\geq 36$ weeks. Outcomes were compared between women with a previous classical CD to those with a prior low transverse CD. Of the 7,936 women who met study criteria, 122 had a prior classical CD. Women with a prior classical $\mathrm{CD}$ had a higher rate of classical uterine incision at repeat CD $(12.73 \%$ versus $0.59 \%$; $p<0.001)$, had longer total operative time and hospital stay, and had higher intensive care unit admission. Uterine dehiscence was more frequent in women with a prior classical CD $(2.46 \%$ versus $0.27 \%$, OR 9.35 , 95\% CI 1.76-31.93). After adjusting for confounding factors, there were no statistical differences in major maternal or neonatal morbidities between groups. Uterine dehiscence was present at repeat $\mathrm{CD}$ in $2.46 \%$ of women with a prior classical CD. However, major maternal morbidities were similar to those with a prior low transverse CD.

\section{Keywords}

cesarean delivery; classical cesarean delivery; prior cesarean; maternal outcomes; neonatal outcomes

\section{INTRODUCTION}

Cesarean delivery (CD) is a term used to describe delivery of a fetus through incisions in the abdominal wall and the uterine wall ${ }^{1}$. In most cases a low transverse uterine incision is performed. Perhaps the most important reason to utilize a low transverse incision is that, by avoiding the contractile portion of the uterus, the patient may be a candidate for a vaginal delivery in subsequent pregnancies. There are several instances when a classical uterine incision may be required, including fetal malpresentation, undeveloped lower uterine segment, placenta previa or accreta, severe bladder adhesions, or the presence of lower uterine segment fibroids2.

Surgical complication rates are greater for classical CD compared to low transverse CD and include higher blood loss, greater need for transfusion, higher infection rates, and more severe post-operative pain. ${ }^{3}$ In future pregnancies, the risk of uterine rupture is also much greater for women with classical $\mathrm{CD}$ compared to those low transverse $\mathrm{CD}^{3}$. It is unknown is whether there is also a higher rate of surgical complications in future pregnancies at the time of repeat CD. 
The objectives of this study are to describe the frequency of adverse maternal and neonatal outcomes at the time of repeat $\mathrm{CD}$ in women with a prior classical $\mathrm{CD}$ and compare these rates with those who had a prior low transverse $\mathrm{CD}$.

\section{METHODS}

The cesarean registry was a prospective, observational, cohort study performed by the Eunice Kennedy Shriver National Institute of Child Health and Human Development Maternal-Fetal Medicine Units Network during the years 1999-2002 ${ }^{4}$. This study, conducted at a total of nineteen academic centers, was designed to collect data on maternal and neonatal outcomes and complications from CD. Approval was granted by the institutional review board of each academic center that participated, as well as the institutional review board of the data coordinating center.

The cesarean registry included all women that had a previous CD and delivered $\geq 20$ weeks with a singleton gestation and a birth weight $\geq 500 \mathrm{~g}$. Trained research nurses at each center reviewed medical records and collected data on standardized forms. Data abstraction methods have been previously described. ${ }^{4}$ Neonatal outcomes were collected until discharge or for up to 120 days after delivery. Data were transmitted to the George Washington University Biostatistics Center where it was stored, monitored and edited for missing or inconsistent data. All cases of maternal death, stillbirth, uterine rupture and hypoxic ischemic encephalopathy underwent a secondary review by study investigators.

This secondary analysis included women with a singleton pregnancy who had one prior CD and underwent repeat $\mathrm{CD}$ without a trial of labor. In order to avoid the confounding effects associated with preterm birth, only those who delivered $\geq$ at 36 weeks 0 days were studied. Women who had a prior low vertical, $\mathrm{T}$, J, or unknown uterine incision were also excluded. For this analysis, labor was defined as cervical dilation $\geq 4 \mathrm{~cm}$ or if oxytocin or cervical ripening agents were administered. Maternal and neonatal outcomes after repeat $\mathrm{CD}$ were compared between women with a prior classical $\mathrm{CD}$ to those with a prior low transverse $\mathrm{CD}$.

In order to analyze for differences in rare events between groups, composite outcomes were utilized. The same composite outcomes were used as previously described in our earlier paper which looked at maternal and perinatal outcomes associated with a trial of labor after prior cesarean delivery ${ }^{4}$. The composite maternal outcome included uterine rupture, uterine dehiscence, hysterectomy, thromboembolic disease, endometritis, blood transfusion or maternal death. Other maternal morbidities studied were need for blood transfusion(s), intensive care unit admission and the presence of placenta accreta. The composite perinatal outcome consisted of antepartum/intrapartum stillbirth, hypoxic ischemic encephalopathy or neonatal death. Other perinatal morbidities analyzed were neonatal intensive care unit admission, 5-minute Apgar scores $\leq 5$, and umbilical-artery blood $\mathrm{pH} \leq 7.0$.

Uterine rupture was defined as a disruption or tear of the uterine muscle and visceral peritoneum or a separation of the uterine muscle with extension to the bladder or broad ligament. Uterine dehiscence was defined as a disruption of the uterine muscle with intact serosa. Postpartum endometritis was defined as a clinical diagnosis of puerperal infection in the absence of findings suggesting a non-uterine source of infection. Fetal deaths that occurred before hospital admission were classified as antepartum stillbirths.

The statistical analysis was performed using SAS (SAS Institute, Cary, NC) and Cytel Studio. Statistical analysis for continuous variables utilized descriptive statistics as well as the Student's T-Test or Wilcoxon rank-sum test, where appropriate. Categorical variables were analyzed using the Fisher's exact test. The exact confidence intervals were calculated for odds ratios. No p-value adjustments were considered for multiple comparisons. Multivariable 
logistic regression was performed to adjust for potential confounding factors including gestational age, maternal age, race/ethnicity, insurance type, smoking status, body mass index (BMI), maternal diseases, neonatal birth weight of the previous $\mathrm{CD}$, and neonatal birth weight of the current delivery. Two-sided p-values are reported with statistical significance defined as $\mathrm{p}<0.05$.

\section{RESULTS}

Over the study period, there were 35,420 women in the cesarean registry who had a singleton gestation with a history of one prior $\mathrm{CD}$; of these 9,766 had repeat $\mathrm{CD}$ prior to labor. After exclusions (GA < 36 weeks [n=212], missing data [ $\mathrm{n}=5$ ], and prior low vertical, $\mathrm{T} / \mathrm{J}$, or an unknown uterine incision $[\mathrm{n}=1,613])$, there were 7,936 women who met all study criteria $(\mathrm{N}=$ 122 prior classical $\mathrm{CD}$ and $\mathrm{N}=7,814$ prior low transverse $\mathrm{CD}$ ).

Demographic and clinical characteristics are described in Table 1. There were a higher proportion of African-American women in the prior classical CD group. This is most likely due to the association between African-American maternal race and preterm birth (i.e. preterm delivery has higher risk for malpresentation and classical CD). Women with prior classical were also more likely to have governmental insurance.

Repeat classical CD was more common in women with a prior classical CD $(12.73 \%$ vs. $0.59 \%$; $\mathrm{p}<0.001)$. Women with a prior classical CD had longer total operative time $(61.44 \pm 21.31$ vs. $51.98 \pm 21.16$ minutes; $p<0.001)$, and a longer hospital stay $(3.49 \pm 2.01$ vs. $3.24 \pm 1.72$ days; $\mathrm{p}=0.01$ ). Major maternal complications were rare in both groups (see Table 2). There were no cases of uterine rupture in either group. Uterine dehiscence and admission to the intensive care unit were more common in women with a prior classical CD. However, there was no difference in the rate of the composite maternal outcome (4.10\% vs. 2.18\%; OR 1.92, $95 \%$ CI 0.60-4.70). After adjusting for confounding variables with multivariable logistic regression, there was still no difference in composite maternal outcomes between groups (OR $=3.31$, CI: $0.91-11.97 ; \mathrm{p}=0.07$ ). Additionally, there were no differences in rates of individual major maternal morbidities between groups. Due to the population being studied (women having repeat $\mathrm{CD} \geq 36 \mathrm{wks}$ ) neonatal complications were very rare and similar between groups. Due to the relatively sample size and infrequency of adverse events, 95\% CI's are extremely wide for group comparisons of both maternal and neonatal outcomes.

There were a total of 5 postoperative maternal deaths (prior classical $\mathrm{CD}=1$, prior low transverse $C D=4$ ). One woman with a prior classical $C D$ who was a Jehovah's Witness refused blood products and died due to complications from severe anemia and disseminated intravascular coagulation. Two women with a prior low transverse $\mathrm{CD}$ died from amniotic fluid embolism. Another women who had sickle cell disease and chronic pulmonary thromboembolism died from cardiac arrest associated with pulmonary emboli. The final death occurred in a women who had morbid obesity (weight $=612$ pounds), gestational diabetes, and prior deep vein thrombosis and pulmonary embolism. She was receiving heparin anticoagulation and died six days postoperatively due to complications of an acute subdural hematoma.

\section{DISCUSSION}

Two novel findings were derived from this analysis. First, women with a prior classical CD undergoing repeat $\mathrm{CD}$ at term have another classical incision in approximately $12 \%$ of cases. Second, $2.46 \%$ of women with a prior classical CD have uterine dehiscence noted at repeat $\mathrm{CD}$. Other key findings include the fact that women with a prior classical CD have similar rates of major maternal and neonatal complications compared to those with prior low transverse CD 
(after adjustment for confounding factors). The absence of differences in outcomes might be explained by the selection of a "lower risk" population (delivery > 36 wks without labor). Thus this study does not allow us to generalize these results to all women with a prior classical CD.

Various reports in the literature have reported maternal complications associated with classical CD. In a single-institution study of women delivering between 1983 and 1995, Greene and colleagues reported that out of 84,299 deliveries of with birth weight $\geq 500 \mathrm{~g}, 8,514$ (10.1\%) had CD and $62(0.073 \%)$ of these were classical CD. ${ }^{3}$ Rates of maternal complications for these women with classical CD were common (49\% infection and $19 \%$ hemorrhage requiring transfusion). Other authors have also reported high maternal complication rates in women with a classical uterine incision5-7.

Strengths of our study include standardized data definitions and collection methods and multicenter involvement. Another strength is that we evaluated outcomes of women with a classical $\mathrm{CD}$ at the time of repeat $\mathrm{CD}$, while prior studies have only evaluated outcomes of the classical CD.

The study also had some limitations. Because we studied only women who had repeat $\mathrm{CD} \geq$ 36 without labor, the low rate of complications may not be applicable to those who present with labor or deliver preterm. Additionally, due to the rarity of adverse outcomes and small sample size of women with prior classical CD, there is relatively low power for statistical comparisons as evidenced by very wide $95 \%$ CIs. Finally, since the majority of the hospitals studied are associated with academic medical centers, these finds may not be applicable to some clinical settings such as non-university based community hospitals.

In conclusion, women with a prior classical $\mathrm{CD}$ are more likely to have a repeat classical $\mathrm{CD}$ and have uterine dehiscence noted at time of repeat CD. Despite this, they have similar rates of major maternal and neonatal morbidity compared with those with a prior low transverse CD. This information may be helpful when counseling women with a prior classical CD.

\section{Condensation}

Compared to those with a prior low transverse cesarean delivery women with a prior classical cesarean delivery have similar rates of major maternal morbidities following repeat cesarean delivery.

\section{Acknowledgments}

The authors wish to acknowledge the following: Sean Blackwell, MD for oversight, Frances Johnson, RN for protocol development and coordination between clinical research centers, and Sharon Gilbert, MS and Elizabeth Thom, PhD for protocol development, data management and statistical analysis.

Supported by grants from the Eunice Kennedy Shriver National Institute of Child Health and Human Development (HD21410, HD21414, HD27860, HD27861, HD27869, HD27905, HD27915, HD27917, HD34116, HD34122, HD34136, HD34208, HD34210, HD40500, HD40485, HD40544, HD40545, HD40560, HD40512, and HD36801).

\section{REFERENCES}

1. Cunningham, GC.; Leveno, KJ.; Hauth, JC.; Bloom, SL.; Gilstrap, L.; Wenstrom, KD. William's Obstetrics. 22nd Ed. McGraw-Hill Companies, Inc; New York: 2005.

2. Gabbe, S.; Niebyl, J.; Simpson, JL. Obstetrics: Normal and problem pregnancies. 5th ed. Churchill Livingstone; Philadelphia: 2007.

3. Greene RA, Fitzpatrick C, Turner MJ. What are the maternal implications of a classical caesarean section? J Obstet Gynaecol Jul;1998 18(4):345-7. [PubMed: 15512105] 
4. Landon MB, Hauth JC, Leveno KJ, Spong CY, Leindecker S, Varner MW, Moawad AH, Caritis SN, Harper M, Wapner RJ, Sorokin Y, Miodovnik M, Carpenter M, Peaceman AM, O'Sullivan MJ, Sibai B, Langer O, Thorp JM, Ramin SM, Mercer BM, Gabbe SG, National Institute of Child Health and Human Development Maternal-Fetal Medicine Units Network. Maternal and perinatal outcomes associated with a trial of labor after prior cesarean delivery. N Engl J Med 2004;351(25):2581-2589. [PubMed: 15598960]

5. Halperin ME, Moore DC, Hannah WJ. Classical versus low-segment transverse incision for preterm caesarean section: Maternal complications and outcome of subsequent pregnancies. Br J Obstet Gynaecol Oct;1988 95(10):990-6. [PubMed: 3191053]

6. Lao T, Halperin SH, Crosby ET, Huh C. Uterine incision and maternal blood loss in preterm caesarean section. Archives of Gynecology and Obstetrics 1993;252:113-117. [PubMed: 8503702]

7. Shah YG, Runner W, Cell CJ, et al. Acute maternal morbidity following classical caesarean section delivery of the preterm infant. Obstetrics and gynecology 1990;76:16-19. [PubMed: 2359565] 
Table 1

Demographic and clinical characteristics of study population.

\begin{tabular}{|c|c|c|c|}
\hline Characteristic & $\begin{array}{c}\text { Prior Classical CD } \\
\qquad=122\end{array}$ & $\begin{array}{c}\text { Prior Low } \\
\text { Transverse CD } \\
\text { N=7,814 }\end{array}$ & P value \\
\hline Maternal age at delivery (y) & $29.21 \pm 5.69$ & $29.62 \pm 5.70$ & 0.44 \\
\hline Race or ethnic group & & & $<0.001$ \\
\hline African-American & $45(36.89 \%)$ & $1,594(20.40 \%)$ & \\
\hline Caucasian & $33(27.05 \%)$ & $4,327(55.37 \%)$ & \\
\hline Hispanic & $36(29.51 \%)$ & $1,523(19.49 \%)$ & \\
\hline Other & $8(6.56 \%)$ & $370(4.74 \%)$ & \\
\hline Married & $60(49.18 \%)$ & $5,448(69.72 \%)$ & $<0.001$ \\
\hline Body mass index pre-pregnancy $\left(\mathrm{kg} / \mathrm{m}^{2}\right)$ & $28.21 \pm 7.92$ & $27.69 \pm 6.92$ & 0.81 \\
\hline Smoker during pregnancy ${ }^{* *}$ & $19(15.57 \%)$ & $909(11.64 \%)$ & 0.20 \\
\hline Governmental insurance & $80(65.57 \%)$ & $3078(39.39 \%)$ & $<0.001$ \\
\hline Maternal disease ${ }^{*}$ & $23(18.85 \%)$ & $1,707(21.85 \%)$ & 0.51 \\
\hline Prior vaginal delivery $* *$ & $46(38.33 \%)$ & $1227(15.77 \%)$ & $<0.001$ \\
\hline Parity & $1[1-2]$ & $1[1-1]$ & $<0.001$ \\
\hline
\end{tabular}

Data expressed as mean $\pm \mathrm{SD}$, median [inter-quartile range], or $\mathrm{n}(\%)$.

Asthma, diabetes, chronic hypertension, seizure disorder, thyroid disease, renal disease, or connective tissue disorder $* *$

Data not available for all patients 
Table 2

Maternal Complications According to the Type of Prior Uterine Incision

\begin{tabular}{|c|c|c|c|}
\hline Characteristic & $\begin{array}{c}\text { Prior Classical CD } \\
\mathbf{N = 1 2 2}\end{array}$ & $\begin{array}{c}\text { Prior Low Transverse } \\
\mathbf{C D} \\
\mathbf{N}=\mathbf{7 , 8 1 4}\end{array}$ & $\begin{array}{c}\text { OR } \\
\text { (95\% exact CI) }\end{array}$ \\
\hline Uterine dehiscence & $3(2.46 \%)$ & $21(0.27 \%)$ & $9.35(1.76-31.93)$ \\
\hline Hysterectomy & $0(0)$ & $12(0.15 \%)$ & $*$ \\
\hline Thromboembolic Disease & $0(0)$ & $3(0.04 \%)$ & $*$ \\
\hline Endometritis & $1(0.82 \%)$ & $98(1.25 \%)$ & $0.65(0.02-3.78)$ \\
\hline Blood Transfusion & $0(0)$ & $47(0.60 \%)$ & $*$ \\
\hline Maternal Death & $1(0.82 \%)$ & $4(0.05 \%)$ & $16.13(0.32-164.40)$ \\
\hline Composite Outcome ${ }^{* *}$ & $5(4.10 \%)$ & $170(2.18 \%)$ & $1.92(0.60-4.70)$ \\
\hline ICU Admission & $2(1.64 \%)$ & $14(0.18 \%)$ & $9.29(1.01-41.08)$ \\
\hline Placenta Accreta & $1(0.82 \%)$ & $4(0.05 \%)$ & $16.13(0.32-164.40)$ \\
\hline
\end{tabular}

Data presented n (\%). Outcome data not available for women.

There were no cases of uterine rupture in either group.

*

-Denotes not applicable

**

- Maternal composite outcome includes one or more of the following complications: uterine rupture, uterine dehiscence, hysterectomy, thromboembolic disease, endometritis, blood transfusion, or maternal death 
Table 3

Perinatal Outcomes According to the Type of Prior Uterine Incision

\begin{tabular}{|c|c|c|c|}
\hline Characteristic & $\begin{array}{c}\text { Prior Classical CD } \\
\mathbf{N = 1 2 2}\end{array}$ & $\begin{array}{c}\text { Prior Low Transverse CD } \\
\mathbf{N = 7 , 8 1 4}\end{array}$ & OR (95\% CI) \\
\hline Antepartum/Intrapartum stillbirth & 0 & $8(0.10 \%)$ & $-^{*}$ \\
\hline Neonatal Death & 0 & $4(0.05 \%)$ & $-^{*}$ \\
\hline Composite Outcome & $* *$ & $12(0.15 \%)$ & $-^{*}$ \\
\hline Admission to NICU & $11(9.02 \%)$ & $694(8.89 \%)$ & $1.02(0.49-1.90)$ \\
\hline 5-minute Apgar $\leq 5$ & 0 & $15(0.19 \%)$ & $-^{*}$ \\
\hline Umbilical-artery blood $\mathrm{pH} \leq 7.0^{* * *}$ & 0 & $22(1.11 \%)$ & $-^{*}$ \\
\hline
\end{tabular}

Data presented as N (\%). Outcome data not available for women.

There were no cases of Hypoxic-ischemic encephalopathy in either group.

* Denotes not applicable

**

- Perinatal composite outcome includes one or more of the following complications: antepartum/intrapartum stillbirth, hypoxic ischemic encephalopathy, or neonatal death.

$* * *$

cord blood gases not available for all patients 